\title{
LOS RETOS DE LA INTEGRACIÓN ECONÓMICA EN AMÉRICA LATINA Y EL CARIBE. UNA APROXIMACIÓN PRELIMINAR AL CASO CUBANO
}

Milagros Elena Martínez Reinosa*

\begin{abstract}
Resumen: Para los economistas cubanos el tema de la integración latinoamericana y caribeña es sumamente interesante. En este artículo la autora sintetiza algunas de esas reflexiones. Inicialmente expone los rasgos que caracterizan actualmente el complejo entorno en que se mueve la integración económica en América Latina y el Caribe, haciendo énfasis en los puntos de encuentros y desencuentros de los esquemas de integración de la región con el proceso integracionista cubano, para finalmente retomar un grupo de ideas -ya apuntadas por otros estudiosos cubanos del tema- que ayudan a comprender los retos a los cuales se enfrenta Cuba al buscar su inserción en los esquemas de integración económica latinoamericano y caribeño.
\end{abstract}

PALABRAS CLAVE: Integración económica, Globalización, Retos, Cuba, América Latina, Caribe.

\section{INTRODUCCIÓN}

En la mayoría de las reuniones celebradas en América Latina y el Caribe se llega a la conclusión común de la necesidad de avanzar en la integración de las naciones de la región como una estrategia de inserción exitosa en el actual contexto globalizado. Ésta permitiría minimizar los riesgos derivados de la propia globalización, incrementar la compe-

* Universidad de La Habana, Cuba (milmarey@yahoo.com). 
titividad internacional, así como negociar en mejores condiciones en los disímiles foros multilaterales donde se define la nueva institucionalidad internacional en la actualidad.

El debate académico en torno a la integración económica de la región latinoamericana y caribeña está entonces presente en el contenido temático de los estudios sobre dicha área geográfica. Abordada desde diferentes disciplinas y, por supuesto, a partir de enfoques multidisciplinarios, los estudiosos cubanos también se involucran. Desde la perspectiva de las ciencias económicas se encuentran las interesantes reflexiones de Oneida Álvarez, Lourdes Regueiro, Tania García, Antonio Romero, Pedro Monreal, entre otras. Precisamente, como parte de esos esfuerzos académicos de los economistas cubanos se desarrolla el proyecto de investigación que da título a este trabajo, y cuyos primeros resultados se ofrecen en estas notas.

En esta presentación se expondrán inicialmente un conjunto de rasgos que caracterizan actualmente el complejo entorno en que se mueve la integración económica en América Latina y el Caribe, haciendo énfasis además en los puntos de encuentros y desencuentros de los esquemas de integración de la región con el proceso integracionista cubano. A continuación, se apuntarán algunas reflexiones que ayuden a comprender cómo se inserta Cuba en los esquemas de integración económica de la región. Finalmente se presentan las conclusiones preliminares que arrojan mis análisis.

Para los economistas cubanos el tema de la integración latinoamericana y caribeña es sumamente interesante y al examinarlo se presentan tanto argumentos a favor como valoraciones críticas condenatorias. La participación de Cuba en estos procesos es un problema menos conocido y estudiado. En este acercamiento al caso cubano no se expone aún el resultado de una investigación terminada, sin duda necesaria, sino que me limito a proponer algunas reflexiones preliminares. Las ideas retomadas aquí parten, esencialmente, de trabajos previos realizados por los doctores Lourdes Regueiro, Oneida Álvarez y Antonio Romero. 


\section{EL COMPLEJO ENTORNO EN AMÉRICA LATINA Y EL CARIBE}

El complejo entorno internacional de los últimos años, caracterizado por el estancamiento económico en los principales países desarrollados, la inestabilidad en los mercados financieros y las contradicciones en el seno del sistema multilateral de comercio, han configurado un cuadro de creciente incertidumbre que ha tenido impactos muy desfavorables sobre las economías y sociedades de Latinoamérica y el Caribe. Los sucesos del 11 de septiembre de 2001 y las transformaciones verificadas en la política externa norteamericana a raíz de dichos eventos presupone una mayor marginación de nuestra región. Además la crisis del multilateralismo, que se ha hecho más evidente con la reciente guerra y el controversial proceso de "reconstrucción" en Irak, ha complejizado en extremo las relaciones internacionales contemporáneas.

Dicho escenario mundial, sumado a las debilidades estructurales e institucionales que comenzaban a hacerse evidentes en las naciones de América Latina desde finales del siglo pasado, precipitó una situación de crisis económica, expresión de cierto agotamiento del patrón de crecimiento asumido.

Esta desfavorable dinámica económica y social se ha manifestado también en recurrentes crisis e inestabilidad política, así como en las crecientes percepciones de "mala calidad" de las democracias en Latinoamérica. Como parte de ello se observa un marcado cuestionamiento del modelo de desarrollo consolidado en la región.

Lo anterior ha impactado negativamente a los esquemas subregionales de integración, generando en ocasiones conflictos comerciales y crisis de confianza en varios de los actores involucrados respecto a la viabilidad de tales empeños. Esto se ha reflejado también en la prioridad, la disponibilidad de los recursos y el grado de ejecución asociados a los diversos compromisos "integracionistas" asumidos por los gobiernos de la región.

Hacia fines del decenio pasado, después de varios años testigos de cierta vigorización en las relaciones intrarregionales, los procesos de in- 
tegración subregional sufrieron los embates originados por la crisis asiática y sus consecuencias, sentidas sobre todo en las naciones sudamericanas.

En los últimos años se ha producido también una "yuxtaposición" de los compromisos integracionistas de la mayoría de los países de la región. Además del Tratado de Libre Comercio de América del Norte (TLCAN) ${ }^{1}$ se crearon otros foros, entre los que se pueden citar a la Asociación de Estados del Caribe ${ }^{2}$ y el G-3. ${ }^{3}$ Un número creciente de acuerdos de libre comercio y cooperación económica (bilaterales, trilaterales o birregionales) entre países o esquemas subregionales fueron firmados — de hecho se estima que en la actualidad coexisten más de 40 instrumentos comerciales preferenciales en el hemisferio-. Esta situación indudablemente se hace más compleja dentro del marco de las negocia-

${ }^{1}$ Tratado de Libre Comercio para América del Norte (TLCAN): Acuerdo económico entre Estados Unidos y Canadá firmado en 1988, al cual en enero de 1994, se incorporó México. Este bloque comercial reúne a una población de 372 millones de habitantes.

2 Asociación de Estados del Caribe (AEC): Firmado el convenio en julio de 1994, se concibe como un organismo de consulta, concertación y cooperación. En 1992, los líderes del Mercado Común Centroamericano (MCCA: establecido en 1960 y compuesto por Costa Rica, El Salvador, Guatemala, Honduras y Nicaragua; cuya sede está en la Ciudad de Guatemala. Reúne a una población de 31 millones de habitantes y, a pesar de que su dimensión es relativamente reducida, por su planteamiento y desarrollo fue durante bastante tiempo uno de los procesos de integración más adelantados en el continente americano) decidieron negociar con CARICOM la formación de una organización regional amplia que incluyera a ambos. Los países del Grupo de los Tres: México, Colombia y Venezuela, participaron en las deliberaciones. Su propósito es promover la integración económica y la creación de un espacio para el comercio libre y la cooperación regional. Está conformada por 25 países miembros - que en conjunto representan una población de 202 millones de habitantes- y 6 observadores. Su sede está en Trinidad y Tobago.

${ }^{3}$ Grupo de los Tres (G-3): Integrado en 1994 por Colombia, México y Venezuela, este acuerdo de libre comercio reúne a los más grandes países y economías de la Cuenca del Caribe, con una población de 149 millones de habitantes. 
ciones dirigidas a la conformación del Área de Libre Comercio de las Américas (ALCA). ${ }^{4}$

\section{LIMITACIONES DE LA INTEGRACIÓN ECONÓMICA EN AMÉRICA LATINA Y EL CARIBE}

Varios análisis han advertido que, junto con el dinamismo mostrado por los procesos y esquemas de integración económica en la región hasta fines de los años noventa, hay evidentes limitaciones que lastran los resultados esperados y la propia eficiencia económica y social de los mismos. Algunos de los problemas actuales de la integración son:

- Como parte del desarrollo de los esquemas subregionales y la "yuxtaposición" de compromisos, los organismos e instituciones de mayor alcance han visto disminuida su capacidad de influencia. Ejemplo de ello es lo sucedido con el Sistema Económico para América Latina (SELA). ${ }^{5}$

- El comercio y la inversión intrarregional, efectos e indicadores de la integración, siguen mostrando — pese a los indudables progresos registrados-que las relaciones recíprocas no son todavía determinantes para la mayoría de los países de la región.

- El enfoque prevaleciente en los esfuerzos de integración aún da un peso predominante a los temas comerciales. De esto deriva la necesidad de promover objetivos y acciones en otras materias donde existan tam-

${ }^{4}$ Aunque actualmente hay quienes consideran que las diferentes esferas de relacionamiento externo, al menos en teoría, son compatibles y complementarias entre sí, en nuestra opinión podrían no serlo efectivamente, a menos que cada país o grupo subregional adopte un conjunto de decisiones coherentes que involucren definiciones de estrategias deseables.

5 Sistema Económico Latinoamericano (SELA): Fundado en 1975, es una organización regional de países de América Latina compuesta por 27 miembros, entre los que se incluye Cuba, para promover la cooperación económica y el desarrollo. Las decisiones son tomadas en conferencias anuales que tienen lugar en Caracas, donde se localiza su sede. Ha tenido un impacto limitado en el debate público y en las políticas. 
bién intereses comunes, tales como la coordinación y armonización de políticas, el desarrollo de la infraestructura, la colaboración cultural, social y científico-técnica.

- Se ha reforzado una de las tendencias de largo plazo observadas en la región: el carácter eminentemente intergubernamental de los esquemas de integración. El avance de la integración ha quedado vinculado a la voluntad de los diferentes gobiernos y coyunturas económicas nacionales, y las instituciones de integración no han podido resolver situaciones surgidas de la falta de cumplimiento de las decisiones a nivel nacional, hecho que adquiere mayor relevancia cuando las crisis económicas recurrentes afectan a la región. Lo anterior reclama un replanteo de la institucionalidad latinoamericana y caribeña, especialmente a nivel regional.

- Se advierten incongruencias o superposición entre los compromisos integracionistas asumidos por cada país en los diferentes esquemas.

Por todo lo anterior, el espacio económico y social unificado de América Latina y el Caribe, que reconocemos nunca se iba a lograr de manera espontánea pues tenía que ser el fruto de la voluntad política y de la cohesión solidaria de los Estados miembros, parece ahora estar más distante. Además de las tendencias anteriormente descritas, sin lugar a dudas la propuesta de creación del $\mathrm{ALCA}^{6}$ apunta a modificar radicalmente el alcance de la "utopía integracionista". Del espacio latino-

${ }^{6}$ Área de Libre Comercio de las Américas (ALCA): Concepto articulado en la Primera Cumbre de las Américas, Miami, diciembre de 1994, y posteriormente desarrollado en reuniones ministeriales y de nivel más bajo, como también en foros de negocios. La Segunda Cumbre de las Américas, Santiago de Chile, abril de 1998, significó el comienzo de las negociaciones multilaterales para el establecimiento del ALCA, que según sus postulados implicaría la eliminación progresiva de las barreras al comercio y a la inversión. El acuerdo apunta a constituir un mercado de alrededor de 800 millones de habitantes. Sin embargo sus críticos señalan acertadamente que ha introducido a la región en un laberinto aún mucho más complejo del que ya existía, al cuestionar en la práctica el principal presupuesto integrador latinoamericano y caribeño. El proceso de negociaciones avanza con dificultades y particularmente los gobiernos de Brasil, Venezuela y Argentina han asumido posiciones que complejizan sensiblemente estas negociaciones. 
americano y caribeño se ha pasado paulatinamente a privilegiar el espacio hemisférico o "panamericano" donde Estados Unidos es actor protagónico.

El futuro de los procesos de integración económica y los retos del desarrollo latinoamericano en el actual contexto mundial exige un esfuerzo denodado, imposible de concretarse con la ausencia de una clara voluntad política de los gobiernos de América Latina y el Caribe para impulsar, sobre nuevas bases, la integración regional. Esto debiera conllevar la elección de un camino pragmático, basado en el aprovechamiento e inclusión de todos los avances existentes en materia de integración, al tiempo que se reformulan y perfeccionan el alcance y la institucionalidad de dicha integración.

\section{EL CASO CUBANO}

Una de las pretensiones del presente trabajo se relaciona con la necesidad de esclarecer las características de la participación actual de Cuba en los procesos de integración y colaboración económica. El limitado alcance de esa intervinculación se explica por las condiciones específicas en que se produce su reinserción en la economía internacional después de la desaparición del sistema socialista mundial — por ende del CAME - y de la obligada reestructuración de su modelo socioeconómico, cuyos rasgos esenciales no corresponden con las tendencias prevalecientes en los países de su entorno geográfico y que imponen su impronta tanto a los procesos de integración regional como a las negociaciones de carácter multilateral en el marco de la Organización Mundial de Comercio (OMC). ${ }^{7}$

7 Organización Mundial del Comercio (OMC): Creada en 1944, es el organismo sucesor del GATT General Agreement on Tariffs and Trade -Acuerdo General sobre Aranceles Aduaneros y Comercio-. Sustituye a este último en todas sus funciones, asumiendo al mismo tiempo nuevas competencias. Está formado por 128 países y su sede está en Ginebra, Suiza. 
Los rasgos y tendencias del entorno regional y global dificultan, más de lo que facilitan, una inserción de Cuba en un proceso de integración con los países del área. Sin embargo entre los variados modelos de integración en marcha y la "utopía integracionista", se vislumbran escenarios realistas en los que la isla podría ampliar su participación en dichos procesos, además de diversificar sus vínculos comerciales y económicos. A continuación profundizaré el análisis de los elementos anteriormente apuntados.

\section{CUBA Y LA INTEGRACIÓN LATINOAMERICANA Y CARIBEÑA. ENCUENTROS Y DESENCUENTROS}

El derrumbe del socialismo en Europa del Este y la posterior desaparición de la URSS representaron para Cuba el colapso de un espacio económico de creación relativamente reciente sobre el cual se había reconstruido su estructura productiva, tecnológica, comercial y de servicios. Ello impuso la necesidad de rearticular sus relaciones con la economía capitalista que se erigía, en adelante, como el espacio principal de inserción.

Paralelamente a estos eventos, en el mundo al que Cuba debe reinsertarse se viene produciendo un cambio hacia un patrón de acumulación, que se asienta sobre la liberalización y desregulación económica, el cual deslegitima las políticas activas de intervencionismo estatal dando lugar a una ruptura del funcionamiento del orden mundial. Por demás, dichas prácticas de política económica ya habían ganado amplio terreno en el área latinoamericana, que no dudó en abrazar los postulados neoliberales como solución de sus problemas económicos.

Por otra parte la acelerada internacionalización de la vida económica y los cambios vinculados con un nuevo patrón productivo, tecnológico y de organización empresarial hacen poco factible una solución estrictamente nacional a las dificultades que enfrenta cualquier país. En este contexto las estrategias nacionales de desarrollo se remiten, cada vez más, a un referente global, cuyos cambios implican también un ajuste 
de acuerdo con el patrón de acumulación del capitalismo mundial. Tal exigencia plantea un desafío particularmente complejo para Cuba, quien busca su reinserción a la vez que preservar su naturaleza socialista, las conquistas sociales logradas y el objetivo de superar los niveles cualitativos de las mismas, afectadas durante la crisis. Todo esto bajo los efectos de un largo bloqueo norteamericano que obstaculiza la reinserción y eleva los costos económicos de la misma.

En el proceso cubano de adecuación a los patrones funcionales vigentes en el entorno se le ha otorgado mayor peso a las relaciones monetario-mercantiles y un papel más activo a la política comercial externa - lo que coincide con la tendencia regional—, no obstante existan diferencias sustanciales con el modelo neoliberal que caracteriza a la mayoría de los países de la región.

En el momento del derrumbe del campo socialista, los espacios europeos y latinoamericanos, incluido el Caribe, se perfilaban como los preferentes a los fines de una relación económica estratégica. De hecho, el comercio cubano en los años noventa se concentra en estas dos regiones, fundamentalmente a partir del año 1994 cuando se inicia el proceso de recuperación económica.

Cuba: Intercambio Comercial por áreas geográficas (\%)

\begin{tabular}{lcccccccc}
\hline & 1994 & 1995 & 1996 & 1997 & 1998 & 1999 & 2000 & 2001 \\
\hline Europa & 46 & 41 & 45 & 41 & 47 & 46 & 43 & 43 \\
América & 35 & 41 & 39 & 40 & 35 & 37 & 41 & 39 \\
Asia & 14 & 14 & 12 & 15 & 16 & 16 & 15 & 16 \\
África & 5 & 3 & 3 & 4 & 2 & 0.7 & 0.6 & 0.6 \\
Oceanía & 0.5 & 0.2 & 0.6 & 0.7 & 0.5 & 0.2 & 0.07 & 1 \\
\hline
\end{tabular}

FueNTE: 1994-2000 Cálculos de Oneida Álvarez y Lourdes Regueiro sobre base de datos de Anuario Estadístico de Cuba 2000, Edición 2001, Oficina Nacional de Estadísticas, La Habana, 2001.

2001: Datos de Informe Económico 2001, Banco Central de Cuba, mayo de 2002. 
Sin embargo, la estrategia cubana de preferencias a la región latinoamericana y caribeña tropieza con no pocos obstáculos. Como ya se señaló, los procesos de integración que tienen lugar hoy en América Latina se asientan en la coincidencia de sus políticas macroeconómicas, caracterizadas por la desregulación económica y la acelerada privatización, y en ese sentido las diferencias estructurales y de funcionamiento de la economía cubana son una limitante para su participación en los procesos de integración en su actual diseño.

La integración concebida en una estrategia de desarrollo para la región latinoamericana y caribeña sería la opción más deseable para la inserción cubana, pero no es menos cierto que una integración de matriz neoliberal y subordinada a Estados Unidos como la que tiene lugar en América Latina no es un marco apropiado para la integración de Cuba.

Para la mayor parte de los países latinoamericanos es Estados Unidos el principal emisor de flujos de inversión y el mayor monto acumulado de inversión también procede de ese país, por lo tanto son inversiones comprometidas con la estrategia de las empresas transnacionales norteamericanas. De igual forma la tecnología y otras formas de financiamiento tienen ese origen, lo que dificulta de manera importante una integración cubana fluida y efectiva.

Por otro lado la obsesiva hostilidad norteamericana hacia la isla no se limita al bloqueo en su diseño tradicional. Utiliza además de la coerción económica, mecanismos extra-económicos para impedir cualquier intento de ampliación de las relaciones cubanas en el ámbito latinoamericano y caribeño.

La reinserción de Cuba en el espacio latinoamericano y caribeño implica desafíos no sólo de orden económico, sino también político, que van más allá de la voluntad cubana e implican la disposición de las contrapartes para establecer una relación que puede crearles fricciones con Estados Unidos, su principal socio económico en el hemisferio.

Asimismo, en el hemisferio coexisten procesos en los que se superponen y entrecruzan las características y aspiraciones de los procesos históricos de integración con las nuevas formas de regionalismo, funciona- 
les a la lógica neoliberal. La emergencia y refuncionalización de los acuerdos regionales en los años noventa ocurrió bajo una orientación económica liberal, y a diferencia de los acuerdos de los sesenta y los setenta el énfasis está en la apertura y no en la protección de los espacios constituidos.

A lo anterior debe añadirse el complejo entramado de acuerdos — se estima que en la actualidad coexisten más de 40 instrumentos comerciales preferenciales en el hemisferio- en los que se entrecruzan diversas formas de concebir la inserción de los participantes en la economía mundial; así como los más disímiles plazos para llegar a los objetivos planteados y una multiplicidad de compromisos que implican diferentes exigencias y obligaciones.

La complejidad no sólo se circunscribe al elevado número de acuerdos en que están involucrados los países latinoamericanos, sino que está especialmente asociada a los objetivos que se proponen lograr. El Sistema de Integración Centroamericano, la CARICOM, la Comunidad Andina, la ALADI y el MERCOSUR se proponen avanzar en el establecimiento de un mercado común, mientras el resto limita sus aspiraciones a la formación de áreas de libre comercio. Esto constituye una diferencia significativa, en cuanto al destino y permanencia en el tiempo de esos procesos pues en el largo plazo, tal como plantea Lester Thurow, si las zonas de libre comercio no evolucionan como en Europa a mercados comunes su destino es la autodisolución. ${ }^{8}$

Los países de la región no sólo están involucrados en acuerdos con otros países del hemisferio. Existen además los acuerdos de países o agrupaciones con la Unión Europea y la participación de México, Chile y Perú en la APEC.

Esto encuentra su explicación en la nueva lógica que sustenta a los procesos de integración, que de ser concebidos como mecanismos para lograr la independencia pasan a ser factores fundamentales para superar la exclusión de los circuitos del capital, aunque ello implique procesos

${ }^{8}$ Entrevista concedida al diario O Estado de São Paulo, 6 de julio, 1997. 
y eventos que consoliden la dependencia. Hoy la integración está mirando más hacia los mercados del Norte, que hacia los países vecinos.

Otro punto de desencuentro es que aunque los esquemas subregionales son hoy los que conforman el núcleo del proceso de integración complementados por los acuerdos bilaterales, no sería arriesgado decir que para la mayor parte de los países del área el ALCA constituye un evento mucho más importante que los acuerdos mismos. De hecho, las negociaciones del acuerdo hemisférico absorben la mayor parte de la inteligencia y los esfuerzos negociadores en el presente. ${ }^{9}$

Tales características de dichos procesos complican la situación cubana para encontrar fórmulas de integración avanzadas con el resto del continente en el plano económico. No sólo por las divergencias económico estructurales y de funcionamiento de las economías, sino también porque aún cuando los esquemas históricos mantienen su objetivo de constituirse en mercados comunes, en la práctica la mayor parte de los acuerdos firmados en la región durante los años noventa se proponen únicamente la constitución de áreas de libre comercio, y quedaría por ver el destino de formas más profundas de integración entre países latinoamericanos post-ALCA.

Atendiendo a este contexto habría que plantearse la pertinencia o no de una integración con áreas cuyo patrón asociativo sea una relación de subordinación a Estados Unidos, con la consiguiente incertidumbre en los compromisos contraídos. También resulta pertinente identificar qué tipos de espacios económicos se están formando en la región, a qué tipo de inserción en la economía mundial tienden, en qué relaciones hegemónicas se estructuran con el fin de diferenciar cada uno de ellos, pues sería simplista asumir que todos los espacios económicos en construcción responden a esa lógica de manera idéntica.

Por otra parte, para Cuba una mayor integración con las naciones de Latinoamérica y el Caribe es fundamental. Las perspectivas del desa-

9 SELA, "Tendencias y opciones en la integración de América Latina y el Caribe", (mimeo), 1998. 
rrollo cubano dependen hoy, entre otros factores, de los avances de la reestructuración económica concebida por el gobierno en un escenario de prioridades sectoriales y de la reinserción en los mercados mundiales, donde la región latinoamericana y caribeña adquiere una dimensión estratégica especial.

Además, los posibles beneficios del acercamiento a los espacios latinoamericanos revitalizan el rescate de la integración latinoamericana como una forma de concebir la inserción en un proyecto de desarrollo nacional.

\section{LAS RELACIONES DE CUBA CON AMÉRICA LATINA Y EL CARIBE}

Cuba mantiene relaciones diplomáticas con los Estados de la región. Cuenta con embajadas establecidas en 29 países; con Costa Rica se desarrollan vínculos consulares. Sólo con El Salvador no se han normalizado las relaciones, y recientemente se interrumpieron con Uruguay después de los hechos ocurridos en los debates en la primavera de 2003 en la Comisión de Derechos Humanos de Ginebra.

La jerarquía otorgada por Cuba a las relaciones con América Latina y el Caribe se manifiesta, entre otras acciones, en la activa participación en organismos regionales como el SELA, CEPAL ${ }^{10}$ y el PARLATINO, ${ }^{11} \mathrm{su}$

${ }^{10}$ Comisión Económica para América Latina y el Caribe (CEPAL): Establecida en 1948, es un organismo regional de Naciones Unidas. Lo conforman todos los países miembros de Naciones Unidas del continente americano y los países extra-continentales que tienen posesiones coloniales. Entre sus funciones prioritarias están el estudio permanente y sistemático de las economías de la región; el análisis de sus tendencias a corto plazo; la elaboración de informes por países; el análisis de las políticas y estrategias de desarrollo como proceso global. Su sede está en Santiago de Chile.

${ }^{11}$ Parlamento Latinoamericano (PARLATINO): Establecido en 1964, para defender la democracia y promover la integración y la cooperación entre los países latinoamericanos. Está conformado por los respectivos parlamentos de 18 naciones. Su sede está en Lima, Perú. 
presencia en acciones de colaboración y cooperación funcional, su voluntad de ser partícipe efectivo en la integración, evidenciada en su membresía en ALADI, en la Asociación de Estados del Caribe (AEC) y en su pertenencia del Grupo ACP (África-Caribe-Pacífico).

Cuba además pertenece a todas las instituciones especializadas del área y ha contribuido a la dinamización de las organizaciones regionales de profesionales, técnicos y científicos. Integra el Movimiento de las Cumbres Iberoamericanas desde su fundación en 1991 y ha asistido a las dos Cumbres de la región con la Unión Europea.

En el plano multilateral se ha manifestado una tendencia creciente a la consolidación de las relaciones de Cuba con el área caribeña. Los países de esta subregión han sido los más activos promotores de la incorporación de Cuba a distintos foros subregionales y regionales. Ciertamente el peso de Cuba desde todo punto de vista en el Caribe confiere "masa crítica" a esa subregión.

Desde el punto de vista económico, el Caribe sería el entorno geográfico más adecuado para la integración de Cuba, ya que se trata de economías menos heterogéneas y que comparten un conjunto de vulnerabilidades; muchas de las cuales son compartidas por Cuba como es el caso de ser zona de desastres naturales.

El comercio de Cuba con la región caribeña no es muy grande, aproximadamente 120 millones de dólares, concentrado en el intercambio con Barbados, Guyana, Trinidad y Tobago y Jamaica. Dadas las dificultades y características del comercio con el Caribe esta cifra no es poco significativa. El desarrollo de las relaciones comerciales de Cuba con la región caribeña se ve limitado por las dificultades del transporte marítimo; Cuba junto con otros países del área ha tomado la iniciativa de establecer algunas líneas marítimas con recorridos regulares por determinadas zonas del área, lo que contribuiría a paliar esta situación. ${ }^{12}$

12 Entrevista realizada a Ricardo Cabrisas, ministro de Gobierno de Cuba publicada por el semanario Opciones, diciembre de 2002, en Internet: http://www.opciones.cubaweb.cu. 
Desde 1993 fue creada la Comisión Conjunta Cuba/CARICOM que ha ayudado a fortalecer el comercio y la colaboración en diferentes áreas como son, entre otras, turismo, medio ambiente, cooperación técnica y atención a desastres naturales. La participación cubana en CARIFORUM, junto con República Dominicana y el CARICOM, es parte de la política de integración al CARICOM. ${ }^{13}$

En el año 2000 fue suscrito un Acuerdo de Comercio y Cooperación entre Cuba y el CARICOM, que es considerado la base para la posterior firma de un Tratado de Libre Comercio para el que aún no se consideran dadas las condiciones económicas, a pesar de la existencia de una decisión política de los gobiernos de ambas partes al respecto.

También se han establecido importantes nexos entre los actores empresariales. En 2001 por acuerdo de la Asociación de Comerciantes e Industriales del Caribe y de la Cámara de Comercio de Cuba se constituyó la Asociación de Empresarios Cuba-CARICOM, cuyo objetivo es identificar soluciones para superar las históricas dificultades del comercio caribeño y contribuir al desarrollo de la integración.

Los países caribeños han reconocido el papel de Cuba en la Maquinaria Negociadora Regional del Caribe ${ }^{14}$ (Caribbean Regional Negotiating Machinery, RNM) entidad que tiene la función y responsabilidad de

${ }^{13}$ Comunidad y Mercado Común del Caribe (CARICOM): Creado el 4 de julio de 1973, reemplazó a CARIFTA (Caribbean Free Trade Association: Asociación de Libre Comercio del Caribe), que había sido fundada en 1965. Sus propósitos son profundizar el proceso de integración y promover el comercio y el desarrollo dentro de la región, así como trabajar por el establecimiento de una política exterior más concertada. Su secretariado está en Georgetown, Guyana. Tiene en la actualidad 15 miembros: Antigua y Barbuda, Bahamas, Barbados, Belice, Dominica, Granada, Guyana, Haití, Jamaica, Montserrat, San Cristóbal y Nieves, Santa Lucía, San Vicente y Granadinas, Surinam y Trinidad y Tobago; además de dos miembros asociados y cinco observadores. Su población alcanza los 5.5 millones de habitantes.

${ }^{14}$ The Havana Declaration on the Thirtieth Anniversary of the Establishment of Diplomatic Relations between Members States of the Caribbean Community and the Republic of Cuba, 8 de diciembre de 2002. 
participar en negociaciones en diferentes ámbitos, con el objetivo de lograr que las reglas del sistema mundial de comercio tomen en cuenta los intereses de las pequeñas islas y estados costeros bajos y económicamente vulnerables como son los del Caribe.

Además, los países caribeños desempeñaron un papel decisivo en el apoyo a la participación de Cuba en el Grupo África-Caribe-Pacífico (ACP). En diciembre de 2000 el Consejo de Ministros del Grupo ACP aprobó la plena integración de Cuba a esa agrupación, una vez se modificara el Acuerdo de Georgetown. ${ }^{15}$ La participación de Cuba en el Grupo ACP ha aportado su visión de lo que deben ser las relaciones Sur-Sur, así como su experiencia de cooperación con muchos países africanos.

Paralelamente el Grupo ACP gana conciencia de que las cuestiones concernientes al trabajo de este no se enmarcan solamente en las relaciones con la Unión Europea (UE). ${ }^{16}$ En la actualidad existen cuestiones relativas al desarrollo que trascienden el marco de la relación bilateral ACP-UE y son discutidas en el seno de la OMC y de otras instituciones de

${ }^{15}$ El Grupo ACP, integrado por 77 miembros, se comprometió a trabajar por la modificación del referido Acuerdo, ya que en su actual formulación no permite la adhesión de países que no mantengan acuerdos de cooperación con la Unión Europea. Granma, 14 de diciembre, 2000.

${ }^{16}$ Unión Europea (UE): Creada por el Tratado de Maastricht de 1992, es el estadio superior de un proceso de integración iniciado hace más de cuatro décadas, y que modifica y amplía el Tratado que estableció las Comunidades Europeas. Sus objetivos son fortalecer la cohesión económica y social; establecer una unión económica monetaria, culminando en una moneda única; implementar una política exterior y de seguridad común; lograr la ciudadanía europea; desarrollar la cooperación en la justicia y los asuntos del interior. La conforman 15 países ( 25 a partir del $1^{\circ}$ de mayo de 2004). Su sede está en Bruselas, Bélgica. Entre los más importantes convenios que ha establecido la UE se encuentran, los Convenios de Lomé y el actual Convenio de Cotonú. El primer Convenio de Lomé fue firmado en febrero de 1975, entre en aquel entonces Comunidad Económica Europea (CEE) y que contaba sólo con 9 miembros y 46 de sus antiguas colonias de África, Caribe y el Pacífico. Se ha renovado desde entonces en cuatro ocasiones, la última en el pasado año 2000, cuando sufrió una sustantiva modificación, pasando de ser un acuerdo de preferencias arancelarias a un acuerdo de preferencias recíprocas, con una vigencia de 10 años más. 
Naciones Unidas. ${ }^{17}$ Sin embargo, es preciso reconocer que las relaciones en el Grupo ACP se articulan en torno a sus relaciones con la UE, ya que las relaciones entre las diferentes regiones representadas en su seno son muy limitadas.

Dentro del marco de la celebración del XXX Aniversario del establecimiento de relaciones diplomáticas entre Estados de la Comunidad del Caribe y Cuba, el presidente Fidel Castro anunció que las condiciones habían cambiado y que Cuba solicitaría su adhesión al Convenio de Cotonú, paso que no había dado antes por las excepcionales condicionantes europeas para la isla, no contempladas para los demás participantes. Este escenario que parecía — a principios de 2003 - que tendría una evolución favorable volvió a complicarse en extremo, cuando en junio de ese mismo año y como consecuencia de la postura asumida por la UE en relación con el tema de los derechos humanos en Cuba se produjo una crisis, que aún continua, de las relaciones del bloque europeo con la isla.

Lamentablemente, esta retirada de Cuba se traduce en la pérdida del disfrute de preferencias arancelarias no recíprocas para varios productos, que a partir del año 2008 serán sustituidas por un régimen liberalizado de intercambios comerciales. Además, el citado convenio preveía la erogación de fondos de cooperación para el desarrollo por un monto de 13500 millones de euros para los primeros cinco años a partir del ingreso de Cuba, que como se conoce estaba fijado para 2003.

La adhesión de Cuba al Convenio de Cotonú habría sido un elemento significativo por sus potencialidades como fuente de financiamiento e inversión que consolidaría la reinserción cubana en los mercados europeos.

En el área del Gran Caribe, Cuba es fundador de la Asociación de Estados del Caribe (AEC) en 1994. Esta agrupación no es estrictamente

17 Entrevista a Jean Robert Goulongana, Secretario General del Grupo ACP, semanario Opciones, noviembre de 2002, en Internet: http://www.opciones.cubaweb.cu. 
un esquema de integración, sino de concertación y cooperación, pero que no descarta acciones tendientes a la integración y ha sido un escenario favorable para la consolidación de iniciativas de cooperación con el área caribeña dado el especial apoyo que ha brindado esta entidad al turismo sustentable. Por ejemplo, con el área del Caribe existe un Plan de Coordinación en este sector para evitar la competencia, así como promover el desarrollo de Programas de Multidestino mutuamente ventajosos.

La AEC ha sido un marco apropiado también para el fortalecimiento de las relaciones con Venezuela, país que en el marco de esa organización ha promovido un Acuerdo de Cooperación Financiera con el Fondo Especial de la OPEP.

Realmente la AEC ha significado un espacio para diversificar el debate latinoamericano en torno a cuestiones del desarrollo y la integración. Sin embargo, desde el punto de vista económico no se aprecia un despegue significativo de las relaciones intra AEC, aunque es necesario reconocer que ha apoyado, y en algunos casos promovido, acciones que ya tenían sus bases en otros espacios.

Como puede inferirse de este resumido recuento de la participación de Cuba en la integración caribeña, existe la voluntad política expresa del gobierno cubano por fortalecer los lazos en todos los ámbitos con esta región, a pesar de que los mecanismos e intereses en juego en esos procesos no siempre se corresponden con sus objetivos y sus deseos respecto al futuro de la región.

\section{RELACIONES DE PARTICIPACIÓN EN LOS ACUERDOS DE INTEGRACIÓN}

En el discurso cubano siempre ha existido una evaluación favorable a los procesos de integración subregional, que incluye la posible participación de Cuba en esos procesos. Sin embargo, en la práctica más extendida, el acercamiento cubano ha sido con países y no a esquemas. Incluso en los casos donde Cuba tiene acuerdos de complementación 
económica con todos los países del esquema, estos son acuerdos independientes y por separado.

En rigor, el único esquema de integración del que Cuba es miembro pleno es el de ALADI, ${ }^{18}$ al que se adhirió como miembro pleno en 1999. Este hecho resulta lógico, pues ALADI es el esquema de integración que por su naturaleza e instrumentos más se adecua a los intereses de Cuba. En ALADI, los procesos de liberalización son más graduales y laxos, preserva de la vieja integración los instrumentos para la integración sectorial lo que se da más en el nivel bilateral que en el regional. Dichos instrumentos se amparan en los Acuerdos de Alcance Parcial y de Complementación Económica.

Es importante precisar que por sus propias características, ALADI no es un esquema de integración de los más dinámicos, se acerca más a un acuerdo cuya filosofía tiende al anterior patrón de acumulación. Existen muchas señales en este sentido. La ALADI no es reconocida como instancia de negociación frente al ALCA, y a pesar de su sólida institucionalidad y desarrollo instrumental no es considerada el eje de convergencia de la integración en América del Sur, papel que el consenso y los medios le otorgan al proyecto conocido por ALCSA (Área del Libre Comercio de Sudamérica) basado en la convergencia CAN ${ }^{19}$-MERCOSUR.

18 Asociación Latinoamericana de Integración (ALADI): Creada en 1980 para sustituir a la ALALC (Asociación Latinoamericana de Libre Comercio), que había sido fundada 20 años antes en Montevideo, Uruguay, y cuyo objetivo era establecer una zona de libre comercio. La ALADI surgió como un reconocimiento del fracaso del proyecto de integración debido a la imposibilidad de respetar los compromisos que los miembros de la ALALC se habían propuesto. Mantiene su sede en Montevideo, Uruguay y su propósito es llegar a constituir un mercado común. Sus miembros son Argentina, Bolivia, Brasil, Chile, Colombia, Ecuador, México, Paraguay, Perú, Uruguay y Venezuela, además hay 17 observadores.

${ }^{19}$ Comunidad Andina (CAN): El acuerdo original fue firmado por Bolivia, Chile, Colombia, Ecuador y Perú en 1969. Venezuela se integró en 1973 y Chile se retiró en 1977. Bolivia, Perú y Ecuador han suspendido su membresía por periodos breves, debido a conflictos bilaterales con otros miembros. Comprende una población de 98 
Igualmente ALADI es uno de los acuerdos de integración vigentes que tiene más riesgos de ser superado por el ALCA, pero todo avance precedente en la creación de un espacio con la participación de Cuba resulta beneficioso para la isla y pudiera ser el germen de un rechazo a los posibles intentos ulteriores de aislamiento post-ALCA.

\section{CUBA: EXPECTATIVAS EN LA INTEGRACIÓN LATINOAMERICANA FRENTE AL ALCA}

Cuba ha sido excluida de las negociaciones para la formación del ALCA. Muchas personalidades y representantes gubernamentales de América Latina, y con mayor fuerza aquellos del Caribe han planteado su desacuerdo con la exclusión como instrumento de presión política. Lo anterior no significa que exista un interés por la parte cubana de ser invitada a participar en un acuerdo de libre comercio de dudosos beneficios para la región, que según reportan algunos estudios especializados consolidaría una posición primario-exportadora y destruiría sectores y puestos de trabajo en rubros de mayor valor agregado, profundizaría la dependencia comercial e inhibiría el desarrollo de capacidades autónomas de tecnología.

No obstante, la incorporación del resto de la comunidad latinoamericana y caribeña al acuerdo hemisférico incidirá en las relaciones entre Cuba y la región, y podría redefinir en el mediano plazo las formas en que Cuba participaría en los procesos de integración del área, aunque ello dependerá del perfil que finalmente adopte el citado acuerdo. Lo

millones de habitantes y su sede está en Lima, Perú. Sus objetivos son promover el desarrollo equilibrado y armónico de sus países, y acelerar su crecimiento mediante la integración económica. Después de 1992, el Pacto Andino llamó a la creación de una zona de libre comercio y, más adelante, a un mercado común integrado en 1995, pero sus éxitos limitados han sido sobrepasados por el surgimiento del MERCOSUR. Actualmente se denomina Comunidad Andina. 
cierto es que la evaluación de los potenciales impactos del ALCA para Cuba es aún una tarea pendiente.

Si se toma en cuenta el peso que tienen los esfuerzos asociativos de los países del área para acceder a formas que les posibiliten un acceso seguro y ventajoso al mercado norteamericano, pareciera entonces que cualquier iniciativa asociativa cubana estaría determinado en gran medida por los derroteros que finalmente tome el ALCA. Entre los escenarios posibles que podrían presentarse listamos los siguientes:

a) Si el ALCA prospera, los esfuerzos negociadores del área en materia de integración se volcarán hacia ese proyecto y el ALCA tendría que ser considerado como una prioridad para Cuba.

b) Si el ALCA logra diluir o vaciar el contenido preferencial de los acuerdos en curso, podría ser de menos interés para Cuba participar en ellos.

c) Si las negociaciones del ALCA como acuerdo único se retrasaran, como puede ocurrir — téngase en cuenta que Brasil podría estar interesado en ganar tiempo formando una masa crítica con el MERCOSUR $^{20}$ y otros aliados que le permita tener mayor peso en la negociación con Estados Unidos-Cuba tendría entonces un compás de tiempo mayor para fortalecer sus relaciones económicas con América Latina y el Caribe.

De manera general habría que observar qué concesiones concretas hacen los diferentes esquemas frente al ALCA, pues algunas podrían poner en juego aquellos elementos que precisamente constituyen una con-

${ }^{20}$ Mercado Común del Sur (MERCosUR): Fundado en 1991 por los presidentes de Argentina, Brasil, Paraguay y Uruguay. Representa una población de más de 200 millones de habitantes y su sede se encuentra en Montevideo, Uruguay. Chile y Bolivia entraron al acuerdo como miembros asociados en 1996 y 1997, respectivamente. Se han iniciado negociaciones con la Comunidad Andina para su asociación. En la actualidad es sustancialmente una zona de libre comercio y una unión aduanera. 
dición para la participación cubana, como la preservación de normas de desempeño a la inversión extranjera. ${ }^{21}$ Con los actuales niveles de autonomía del capital financiero, y teniendo en cuenta que los desequilibrios financieros son una fuente de ganancias para este segmento del capital, si la liberalización financiera llegase a constituir un requisito, ello significaría para Cuba la introducción de otros elementos de vulnerabilidad que podrían poner en riesgo incluso la estabilidad del sistema.

En cuanto a la participación cubana en el ALCA, estar excluidos es políticamente inaceptable. Económicamente, si sigue una agenda similar a la de TLCAN no resulta económica, ni políticamente conveniente para la isla participar en ella, pero la no participación cubana reporta algunos inconvenientes, como son:

- La exclusión del acceso de Cuba a flujos de capital cuya aspiración sea entrar al mercado norteamericano, lo que significaría el encarecimiento del proceso inversionista en la isla.

- Al no tener acceso Cuba al mercado norteamericano se limitaría la compra tanto de bienes de consumo como productivos cubanos por parte de agentes económicos de América Latina y del Caribe.

- Los acuerdos derivados de las negociaciones del ALCA pueden erigirse en un referente global perverso en temas que son interés de Cuba.

Para una mayor compresión de los impactos del avance y consolidación del ALCA para Cuba se impone un repaso de la evolución y estado actual de las relaciones económicas entre Cuba y Estados Unidos.

${ }^{21}$ Las cláusulas de desempeño a la inversión extranjera forman parte de una política industrial que está cuestionada y desechada no sólo en la letra del TLCAN, sino que la OCDE a través del AMI desplegó la discusión de acciones tendientes a desmontar lo que queda de regulación en el tema de inversión extranjera en una clara intención de dar garantías a las empresas trasnacionales, discusión en la que hasta el momento los países en desarrollo han participado de manera limitada como observadores, aunque después del fracaso del AMI la discusión pretende instalarse en la OMC. De cualquier forma, es previsible que este tema será objeto de conflictividad entre las naciones del Norte y el Sur, con la paradoja que de ser aprobado, los países no firmantes podrían verse excluidos de los flujos de capital. 
Desde fines de 2001, después del paso del huracán Michelle por la isla, y al amparo de una ley aprobada por el Congreso en el año 2000 bajo las presiones de sectores del Legislativo para la reducción y/o eliminación del bloqueo que permite la venta limitada y al contado de alimentos y medicinas a Cuba, se ha producido un incremento de las compras cubanas de alimentos a productores privados norteamericanos. Estos últimos aprecian el mercado cubano como un potencial receptor de sus productos, teniendo en cuenta las importaciones anuales en ese rubro que realiza el país, además de reconocer que el actual comercio con Cuba da empleo a 200000 personas en su país. La siguiente tabla da cuenta de la evolución de esos intercambios.

Intercambio Comercial Cuba-Estados Unidos (millones de dólares)

\begin{tabular}{lccccccccccc}
\hline & 1992 & 1993 & 1994 & 1995 & 1996 & 1997 & 1998 & 1999 & 2000 & 2001 & $2002^{*}$ \\
\hline $\begin{array}{l}\text { Exportaciones } \\
\text { Importaciones }\end{array}$ & 1.20 & 2.50 & 4.60 & 5.60 & 5.50 & 9.50 & 3.50 & 4.50 & 6.90 & 7.10 & 109.40 \\
\hline
\end{tabular}

FUENTE: US Trade Balance with Cuba, U.S. Census Bureau, en (http://www.census.gov). *enero-septiembre

Resultados más ventajosos para el país podrían obtenerse del desmantelamiento del bloqueo sin necesidad de pagar los costos de participar en un área de libre comercio hemisférica. Obviamente, en el corto plazo sería más conveniente para Cuba la solución del tema del bloqueo, lo cual de por sí es un desafío, mayor que la participación cubana en el ALCA.

Si Cuba tiende a convertirse en una economía de servicios, la importación de bienes de Estados Unidos podría ser ventajosa para ambas partes. Además, esto facilitaría el acceso a otros capitales y reduciría los costos de transacciones con terceros motivados por la imposibilidad de poder realizar operaciones directamente con dólares con las consecuentes pérdidas de la conversión a otras monedas. 


\section{BALANCE PARA UN ACERCAMIENTO DE CUBA A LOS PROCESOS DE INTEGRACIÓN}

En esta dirección se puede delinear una estrategia, que parta de identificar la situación actual, caracterizada por los rasgos que a continuación se exponen.

Constituyen indiscutibles fortalezas de Cuba:

- La disposición del gobierno cubano para negociar, lograr entendimientos recíprocos y buscar nuevas y más profundas formas de relacionamiento. - El proceso de reestructuración económica del modelo cubano, especialmente las transformaciones operadas en el sector externo, que ha conducido a cierta descentralización, aparición de nuevos agentes económicos, mayor utilización de los mecanismos monetario-mercantiles y adecuación a los acuerdos de la OMC.

- Alto nivel de calificación de los recursos humanos del país.

- Existencia de un sector emergente, con tendencia a la terciarización de la economía, donde Cuba tiene especiales potencialidades de complementariedad económica, particularmente en el turismo y otros servicios.

- Ventaja situacional, derivada de la ubicación geográfica de Cuba. Sin embargo, no pueden subestimarse las siguientes debilidades:

-Alta vulnerabilidad del sector externo, que se expresa en la dependencia de muy pocos renglones de exportación, en su mayoría de demanda estancada o en retroceso en los mercados mundiales, y por el elevado endeudamiento externo que dificulta las negociaciones financieras $\mathrm{y}$ comerciales.

- Insuficiente ahorro nacional para sostener un dinámico proceso de recuperación de la economía.

- Discrepancias entre el modelo de alta liberalización y desregulación prevaleciente en la región y el modelo cubano.

- Insuficientes vínculos recíprocos, por escaso desarrollo de las vías de comunicación y del conocimiento mutuo a nivel de todos los agentes económicos protagónicos de la región, especialmente en el eslabón empresarial. 
Contribuyen a la agudización de las anteriores dificultades, algunas amenazas entre las que merecen destacarse:

-El bloqueo y el reforzamiento del interés de Estados Unidos por aislar a Cuba.

- La perspectiva de una integración ulterior de los procesos integracionistas de la región en un Área de Libre Comercio Hemisférica, donde resultará inevitable la hegemonía norteamericana, y de cuyo proceso negociador Cuba está excluida.

- Insuficiente integración real de la economía cubana con el resto de la región, especialmente en las esferas financiera y productiva.

- Los reclamos de algunas fuerzas de la región sobre mayores y más aceleradas transformaciones en el sistema cubano.

- El hecho de que Cuba no constituye una prioridad inmediata para la región, y no existen señales concretas para la isla de compromisos esenciales de asociación en el corto plazo, excepto con el Caribe.

No obstante los anteriores argumentos, se presentan en la actualidad un conjunto de oportunidades para Cuba, entre las que merecen destacarse: - Atracción del mercado cubano para los pequeños y medianos capitales de la región, por encontrarse libre de la interferencia de la competencia norteamericana.

- Demandas insatisfechas en la región de servicios educacionales, de salud, científico-técnicos, deportivos y otros, en los cuales Cuba posee prestigiosos resultados.

- Una mayor alianza estratégica con la región puede contribuir a inhibir posteriores acciones de Estados Unidos contra Cuba, y a contrarrestar la influencia de ese gobierno sobre otros agentes del área.

- La condición de Cuba de país miembro de la ALADI y la existencia de Acuerdos de Alcance Parcial con muchos de sus miembros.

- La no integración de Cuba a ningún acuerdo subregional como miembro pleno le favorece para adoptar fórmulas flexibles de mayor intervinculación con cualquiera de ellos.

Tomando en consideración el diagnóstico precedente, Cuba podría potenciar sus fortalezas, explotar al máximo las oportunidades, tratar de 
atenuar sus debilidades, para así estar en mejores condiciones de enfrentarse a las amenazas.

A continuación listamos un grupo de acciones susceptibles de ser evaluadas en función de lograr un mayor acercamiento cubano a la región de América Latina y el Caribe:

1. Continuar fortaleciendo gradualmente la alianza recíproca entre todos los agentes protagónicos de la integración, especialmente empresarios, instituciones financieras y otros, sin abandonar las relaciones gubernamentales.

2. Priorizar la atención a las negociaciones para reducir el endeudamiento externo, utilizando todas las variantes y novedosas alternativas posibles, al tiempo que se perfeccionan los mecanismos de relacionamiento financiero.

3. Continuar avanzando en el proceso de homologación del sector externo cubano, para incrementar la integración con la región especialmente en los sectores comercial, turístico y de servicios.

4. Perfeccionar la estructura productiva, la calidad y los canales de comercialización de los productos exportables cubanos de alta tecnología, que pueden disfrutar de nuevas cuotas de mercado en la región.

5. Desarrollar y aplicar una concepción de exportación de servicios cubanos intensivos en fuerza de trabajo altamente calificada, especialmente en sectores como el educativo, de salud, deportes y otros, sin abandonar la colaboración desinteresada a los estratos de población más vulnerables.

6. Aprovechar la privilegiada situación geográfica de Cuba para insertarse en esquemas regionales de comunicaciones y transporte aéreo y naval con otros miembros de la región, al estilo de los ya ensayados con anterioridad bajo los auspicios del SELA.

7. Continuar estudiando y ampliando las posibilidades de ofertas a la región de servicios industriales, de construcción y mantenimiento, en las áreas donde Cuba ha acumulado mayores experiencias, vinculándolos con exportaciones tradicionales como cemento, acero y otras. 
8. Ampliar las propuestas de Cuba como destino turístico de la región, elaborando planes conjuntos con otros países del Caribe, para así disponer de un producto turístico más diversificado y de mayor calidad.

9. Diversificar y profundizar los vínculos recíprocos con distintos factores de la región, especialmente centros educacionales, científicos, intelectuales, asociaciones de profesionales, organizaciones no gubernamentales y otros.

10. Fortalecer el diseño, realización y aplicación de investigaciones conjuntas sobre temas de especial interés común, como el de la seguridad alimentaria, ahorro y búsqueda de nuevas fuentes de agua y de energía, conservación medio ambiental, prevención de catástrofes naturales, turismo sustentable, y otras.

De todo lo antes expuesto se infiere la importancia que tiene para Cuba lograr un mayor relacionamiento con los procesos de integración de América Latina y el Caribe, objetivo que debe alcanzarse bajo una fórmula que no obligue al país a concesiones o imposiciones ajenas a la naturaleza de su sistema socioeconómico.

De la capacidad y habilidad de los agentes protagónicos cubanos para diseñar y aplicar una estrategia flexible y ventajosa para todas las partes dependerá el éxito. Para el gobierno cubano se impone continuar combatiendo el aislamiento, objetivo priorizado de la política exterior cubana y que constituye en sí mismo un reto pues debe desenvolverse en una coyuntura en la cual la integración plena a cualquier esquema subregional presenta definitivamente muchas interrogantes sin respuestas.

\section{CONCLUSIONES}

El proceso de integración en América Latina y el Caribe discurre en un contexto internacional y regional muy complejo, por la crítica situación económico-social de la mayoría de sus países, la repercusión negativa 
de la desaceleración de la economía mundial y los efectos desintegradores que ejerce el proceso de negociación con Estados Unidos para conformar un Área de Libre Comercio de las Américas (ALCA) en el año 2005, que consolidaría sus intereses geoestratégicos sobre la región.

La integración económica y la concertación política en esta área geográfica exigen una férrea voluntad y apoyo de los agentes gubernamentales, privados y sociales, todo indica que sería la única palanca capaz de poner a la región en mejores condiciones frente a sus debilidades internas y amenazas externas. El aumento de la capacidad de negociación de América Latina y el Caribe es también necesario para colocar la defensa de sus intereses en los escenarios multilaterales y en foros internacionales.

El ALCA es el principal obstáculo actualmente en la búsqueda de un camino propio para los procesos de integración de la región, que favorezcan el desarrollo endógeno y la búsqueda de caminos alternativos al modelo neoliberal aplicado en las últimas décadas, el cual ha tenido negativos resultados para la mayoría de los ciudadanos.

La región de América Latina y el Caribe está priorizada en la política exterior del gobierno cubano. Las relaciones diplomáticas se han normalizado paulatinamente, con episodios de inestabilidad por presiones externas. De igual forma los vínculos económicos se han ampliado desde inicios de los años noventa. Son fuertes los nexos en el nivel de diferentes agentes económicos y de la sociedad civil, y muy sólidos los programas de cooperación en disímiles esferas científico, técnicas y sociales. Es destacable la voluntad política por reforzar todas esas interconexiones, por vías bilaterales y multilaterales.

$\mathrm{El}$ avance de negociaciones más profundas también se ha visto limitado por el mayor protagonismo que ha adquirido en los últimos tiempos la Organización de Estados Americanos (OEA) ${ }^{22}$ —organismo internacional este que por influencia norteamericana excluyó a la isla de

22 Organización de Estados Americanos (OEA): En Bogotá en 1948, se elaboró la Carta de la OEA, que dio una estructura jurídica contractual a una organización regional de acuerdo con las Naciones Unidas. Sus propósitos declarados plantean que trabaja 
su seno a principios de la década de los sesenta- así como por el dinamismo reciente del Grupo de $\mathrm{Rí}^{23}$ al que nunca Cuba se ha incorporado. La ausencia cubana en esos dos foros regionales limita la proyección de sus concepciones e influencia en los temas allí debatidos y en las acciones acordadas.

Sin transformaciones profundas en los actuales modelos de integración de la región, resulta difícil la participación plena en ellos de Cuba por la incompatibilidad del modelo cubano con los mecanismos esenciales de funcionamiento económico, y los objetivos pretendidos en los ya citados modelos de integración latinoamericano y caribeño. No obstante, existen fórmulas flexibles de mayor vinculación de la isla con los

por la paz y la justicia y por promover la solidaridad entre los Estados americanos; reafirmar su colaboración y defender su soberanía, su integridad territorial y su independencia; promover su desarrollo económico, social y cultural ; y fomentar el proceso de integración económica. Su sede está en Washington, D.C., Estados Unidos. Está compuesta por 35 miembros y 31 observadores permanentes. Cuba fue excluida en 1962.

${ }^{23}$ Grupo de Río: Creado en 1986 para promover la democracia, y más tarde, el comercio y la integración económica en la región. Pertenecen a este organismo 12 países latinoamericanos: Argentina, Bolivia, Brasil, Chile, Colombia, Ecuador, México, Panamá, Paraguay, Uruguay y Venezuela, que representan una población de 300 millones. A fines de los años noventa era uno de los foros políticos más importantes de América Latina y el Caribe. Cuba y República Dominicana han expresado interés en formar parte, pero ello no se ha materializado. Tuvo su origen en el Grupo de Contadora, constituido en 1983 por Colombia, México, Panamá y Venezuela como una iniciativa regional para la búsqueda pacífica y negociada a la solución del conflicto de América Central. En 1985, se estableció el Grupo de Apoyo a Contadora, al incorporarse Argentina, Brasil, Perú y Uruguay. Si bien esto contribuyó a vigorizar este mecanismo mediador, al mismo tiempo cambió su carácter al hacerse más sudamericano e integrado por países que recientemente habían pasado de regímenes dictatoriales a procesos democráticos. A fines de 1986, ambas instancias se constituyeron en el Grupo de los Ocho y se creó el Mecanismo Permanente de Consulta y Concertación Política, aunque Contadora y Apoyo continuaron trabajando hasta 1987. A partir de la suspensión de Panamá en 1988, en lugar del Grupo de los Ocho se comienza a llamar Grupo de Río, exigiendo la condición de la democracia como requisito para ser miembro. 
mismos, lo cual posibilitaría beneficios recíprocos y una participación activa por la parte cubana, en el diseño de nuevas alternativas de cooperación regional que satisfagan los intereses de los pueblos.

En el actual contexto definido por el perfil de los procesos de integración que se desarrollan en la región y por las amenazas que sobre ellos se cierne con el ALCA, así como por la estructura cuantitativa y cualitativa de las relaciones comerciales de Cuba, pareciera que en el corto plazo y desde una perspectiva económico comercial las opciones asociativas más ventajosas estarían limitadas a la consolidación de acuerdos sectoriales en el marco de la ALADI y de cooperación en diversas áreas del turismo en la región del Caribe.

Otra proyección podría tener la presencia cubana en los procesos de integración, si la actual visión comercialista de los mismos incluyera matices que indicaran una cierta jerarquización de la dimensión política de la integración.

Para Cuba el ALCA no es una opción aceptable. No obstante, ser excluidos de ese instrumento comercial puede tener consecuencias muy negativas en sus relaciones con el resto de la región, lo que debe ser cuidadosamente evaluado por el gobierno cubano.

\section{BIBLIOGRAFÍA}

ÁlAmos, Pilar et al., Integración económica y democratización: América Latina y Cuba, Santiago de Chile, Instituto de Estudios Internacionales, 1998.

Álvarez, Oneida y Lourdes Regueiro, "Reflexiones sobre la integración económica. La participación de Cuba", Documento interno del Centro de Estudios sobre América, La Habana, 2002

Alzugaray Treto, Carlos, "Globalización e integración regional en América Latina y el Caribe: un estado del debate", Revista Temas, núm. 14, abril-junio, 1998, pp. 122-131.

Anuario Estadístico de Cuba 2000, Edición 2001, La Habana, Oficina Nacional de Estadísticas, 2001. 
Banco Central de Cuba, Informe Económico 2001, BCC, mayo, 2002.

CABRISAS, Ricardo, "Ministro de Gobierno de Cuba. Entrevista", Semanario Opciones, diciembre, 2002, pp. 4-5. En Internet: (http:// www.opciones. cubaweb.cu).

CASTRO RUZ, Fidel, Globalización neoliberal y crisis económica global. Selección de discursos y declaraciones, mayo 1998-enero 1999, La Habana, Oficina de Publicaciones del Consejo de Estado, 1999.

CEPAL, América Latina y el Caribe: 15 años de desempeño económico, 1980 1995, Santiago de Chile, 1996. , Crecer con Estabilidad, Santiago de Chile, 2000. , Equidad, Desarrollo y Ciudadanía, Santiago de Chile, 2000. , Estudio Económico 1999-2000, Santiago de Chile, 2000. , Estudio económico de América Latina y el Caribe 2000-2001, Santiago de Chile, 2001.

, Panorama de la Inserción Internacional de América Latina y el Caribe, Santiago de Chile, 2001.

Declaración de La Habana en el XXX Aniversario del establecimiento de relaciones diplomáticas de Cuba con los Estados miembros de la Comunidad del Caribe, 8 de diciembre de 2002, Documento MINREX.

Economía Internacional, tomo II, La Habana, Editorial Félix Varela, 2001, pp. 40-133.

GARCÍA LORENZO, Tania, "La integración en la cuenca del Caribe. Institucionalidad y realidad", Revista Temas, núm. 6, abril-junio, 1996, pp. 49-56.

Goulongana, Jean Robert, "Secretario General del Grupo ACP", Semanario Opciones, noviembre, 2002, pp. 4-5. En Internet (http://www.opciones. cubaweb.cu).

IRELA, Cooperación al desarrollo con América Latina hacia un menor protagonismo europeo, Madrid, 1999.

Martínez Reinosa, Milagros y Antonio Romero Gómez, Proyecto de investigación sobre "Los retos de la Integración económica en América Latina y el Caribe". Cátedra Extraordinaria "José Martî", México, CCyDEL-UNAM, julio de 2003.

, "La coyuntura actual de las relaciones entre Cuba y Estados Unidos", en Encuentro de académicos: Cuba en la UNAM, México, CCyDEL, 2004, pp. 155-177.

Morales, Josefina, "La reforma económica en Cuba", en México-Cuba 19022002. Cátedra Extraordinaria "José Martí", México, CCyDEL-UnAM, 2003, pp. 125-151. 
PNUD, Informe sobre el Desarrollo Humano1997, Ediciones Mundi-Prensa, 1997.

, Informe sobre el Desarrollo Humano 1998, Ediciones Mundi-Prensa, 1998.

, Informe sobre el Desarrollo Humano, 1999, Ediciones Mundi-Prensa, 1999.

, Informe sobre el Desarrollo Humano, 2000, Ediciones Mundi-Prensa, 2000.

REgueIRo BELLO, Lourdes María, "La integración latinoamericana: apuntes para un debate", Revista de Ciencias Sociales de la Universidad de Puerto Rico, Recinto de Río Piedras, San Juan, 1997, pp. 110-134.

SANTANA HERNÁNDEZ, Adalberto, "México-Cuba: economía e integración", en México-Cuba. 1902-2002. Cátedra Extraordinaria José Martí, México, CCYDEL-UNAM, 2003, pp. 107-124.

SELA, Tendencias y opciones en la integración de América Latina y el Caribe, mimeo, 1998.

SUÁREZ SALAZAR, Luis, Madre América. Un siglo de violencia y dolor, 18981998, La Habana, Editorial de Ciencias Sociales, 2003.

Thurow, Lester, "Entrevista", diario O Estado de São Paulo, 6 de julio, 1997. VALDÉS PAZ, Juan, "La globalización: una mirada desde la izquierda. Mesa Redonda", Revista Temas, núm. 5, enero-marzo, 1996, pp. 73-90. 